Original article (short paper)

\title{
An After-School, high-intensity, interval physical activity programme improves health-related fitness in children
}

\author{
Sergio Reloba Martínez \\ Luis Javier Chirosa Ríos \\ Ignacio Martín Tamayo \\ Universidad de Granada, Granada, España \\ Laura Guerrero Almeida \\ Universidad de Sevilla, Sevilla, España \\ Miguel Angel López-Gomez \\ Universidad de Granada, Granada, España \\ Christian Campos Jara \\ Universidad Andrés Bello, Santiago, Chile
}

\begin{abstract}
Health problems related to a low level of physical activity (PA) in children and adolescents have prompted research into extracurricular PA programs. This study was designed to determine the effects of two different levels of PA on the health-related fitness of school children. Ninety-four girls and boys (7-9 years) were randomly assigned to a control group (CG) or intervention group (IG). Over a 12 week study period, children in the CG participated in a similar PA program to that of a standard school physical education program while those in the IG completed a high intensity interval training (HIIT) program. Both programs involved two 40 minute extracurricular sessions per week. Our findings indicate that the HIIT intervention improved motor capacity (speed/agility), Vpeak, $\mathrm{VO}_{2 \mathrm{~m}}$ ax and excess post-exercise oxygen consumption (EPOC) $(p<0.05)$ along with the musculoskeletal capacity of the lower trunk (mean propulsive velocity and standing long jump, $p<0.05$ ). The PA program had no effect on anthropometric variables or hand-grip strength. The data indicate that a 12 week strength training program using workloads adapted to children may significantly improve several markers of health and physical fitness compared to a standard school PA program.
\end{abstract}

Keywords: children, physical condition, aerobic training, high intensity, health, Alpha-fitness

\section{Introduction}

Concern about growing sedentary behaviour, overweight and obesity $^{1,2}$ along with reduced physical activity (PA) among children ${ }^{3,4}$ has recently prompted a series of investigations designed to assess the benefits of extracurricular PA programs ${ }^{5-7}$. Such studies have indicated beneficial effects of PA interventions on various health and fitness markers ${ }^{8-12}$ as well as diminishing sedentary habits ${ }^{13,14}$.

However, authors such as Leek ${ }^{15}$ and Myer and Faigenbaum ${ }^{16}$ have argued that these PA interventions currently do not guarantee that young people attain the levels of health and PA recommended by the different organizations and authors. This has sparked an exponential increase in research on the impact of extracurricular $\mathrm{PA}^{9,16,17-26}$.

As may be inferred from the vast amount of literature available on the topic, most PA interventions involve moderateintensity aerobic PA, or so-called moderate-intensity training (MIT), and are based on working techniques similar to those of a traditional school physical education (PE) program ${ }^{9,17-20}$. However, over the past 10 years, several complementary studies have started to emerge that suggest that high-intensity intermittent aerobic exercise, otherwise known as high-intensity interval training (HIIT), adapted for children and preadolescents ${ }^{21-25}$ shows a beneficial effect on cardiovascular health and fitness ${ }^{16,26}$. This type of PA program has been proposed as an alternative to the conventional school PE syllabus.

For HIIT, Baquet, Van Praagh and Berthoin ${ }^{27}$ suggested a relative exercise intensity of $\geq 80 \%$ of the maximum heart rate to produce significant changes in the maximal oxygen consumption $\left(\mathrm{VO}_{2 \mathrm{~m}} \mathrm{ax}\right)$ of prepubertal children. Myer and Faigenbaum ${ }^{16}$ targeted neuromuscular development and motor skills to improve the health of young children while Naclerio and Faigembaum ${ }^{28}$ highlighted the efficacy of high-intensity exercise in improving the health and fitness of school children. Other authors have also described positive effects of HIIT programs on growth and development ${ }^{29-31}$, along with improved postural control and stability $^{32}$, a spontaneous increase in PA during the day ${ }^{33}$, and a reduced risk of injury while playing sport ${ }^{16}$.

Despite the well-established beneficial effects of MIT and in smaller measure, HIIT, to the best of our knowledge no study has compared the effects of both training strategies on 
the health-related fitness of children. In addition, the different variables and training protocols such as duration, frequency, volume and intensity assessed along with intervening factors such as nutrition education ${ }^{17,34,35}$ and healthy habits ${ }^{13,36}$ hinder indirect comparisons between the two PA intervention strategies.

This study was designed to determine the effects of a moderate-intensity PA and a high-intensity interval PA program on the health-related fitness of school children. As markers of health and fitness, we used the Alpha-fitness battery of tests designed for children and adolescents ${ }^{37-39}$ along with several other frequently used markers. A further objective of this study was to assess the use of the Alpha-fitness test battery and of the indicators, $V O_{2 m} a x$, excess post-exercise oxygen consumption (EPOC) and mean propulsive velocity of the lower trunk (MVprop) in school children.

\section{Methods}

\section{Subjects}

The study participants were 52 boys and 42 girls, aged 7-9 years (mean $8.2 \pm 0.7$ years) randomly assigned to a control group (CG, $\mathrm{n}=56 ; 34$ boys) that took part in an extracurricular moderate-intensity aerobic PA program or an intervention group (IG, $\mathrm{n}=38 ; 18$ boys) that participated in a similar duration high-intensity interval training (HIIT) PA program The age range selected was based on criteria that identify the onset of neuromuscular coordination in children ${ }^{28}$. The sample selection criteria were: 1) belonging to the second cycle of primary school education (ages from 7 to 9); and 2) Having a higher attendance than $90 \%$ in the programs over $90 \%$ of program assistance The exclusion criteria were: 1 ) any illness suggesting possible difficulty in completing the study in the 3 months prior to its onset; and/or 2) any medical or orthopaedic problem that could impair completion of the exercise program. All the participants (and their parents or legal guardians) were informed of the procedures involved and possible risks and/or benefits. The study protocol was approved by the Bioethics Committee of the Universidad de Granada (Granada, Spain) and adhered to the tenets of the Declaration of Helsinki. All parents/legal guardians signed a written consent form.

\section{Experimental design}

The study consisted of a pre-posttest with natural groups that had similar characteristics. The extracurricular intervention was performed during the two hours per week of physical education $(\mathrm{PE})$ on the primary school timetable. The groups did not engage in regular PE classes. Instead, they followed the two programs offered. Five groups were randomly assigned to either program.

The following indicators of fitness and health were used as dependent variables: maximum oxygen consumption $\left(\mathrm{VO}_{2}\right.$ $\mathrm{m}$ ax); peak velocity (Vpeak); hand-grip; - grip; jumping ability; lower trunk mean propulsive velocity (MVprop); excess post-exercise oxygen consumption (EPOC); percentage of fat mass ( $\%$ body fat); body mass index (BMI); and waist circumference. PA practised by the participants was employed as an independent variable.

\section{Data acquisition and measurements}

To compare the two interventions, the following tests were performed before and after each program. All the participants took part in several practice sessions before each set of tests.

Alpha-fitness. An explanation of the tests that were performed follows. a) Maximum oxygen consumption $\left(\mathrm{VO}_{2 m} a x\right)$. As a measure of aerobic capacity, $\mathrm{VO}_{2 \mathrm{~m}}$ ax was determined in the $20 \mathrm{~m}$ shuttle run test. For the test, subjects ran $20 \mathrm{~m}$ (there and back) in time with an acoustic signal. The signal sets a starting velocity of $8 \mathrm{~km} / \mathrm{h}$, which thereafter increases by $1 \mathrm{~km} \cdot \mathrm{h}^{-1}$ each minute. The test ends when the subject cannot keep up with the rhythm set. The authors of the Alpha-fitness test battery express the test results as the "stage' completed by the subject. However, we indirectly calculated $\mathrm{VO}_{2 \mathrm{~m}}$ ax by entering the maximum velocity recorded for each subject in the equation described by Leger, Mercier, Gadoury and Lambert ${ }^{40}$ for children under 18 years of age. b) Peak velocity (Vpeak). As a further measure of aerobic capacity, we determined Vpeak as the maximum velocity recorded before the child abandoned the $20 \mathrm{~m}$ shuttle run test. c) Speed/agility. As a measure of motor capacity, speed/agility was determined in the $4 \times 10 \mathrm{~m}$ shuttle run test. In this test, the subject runs $10 \mathrm{~m}$, picks up a cone, returns to the starting line, switches the cone for another cone and continues the process until he/she covers $4 \times 10 \mathrm{~m}$. The result is expressed in seconds. d) Hand-grip. Hand strength (right and left) was measured by dynamometry in kilograms. e) Jumping ability. The distance jumped in a standing long jump was recorded in centimetres. Starting with the legs at shoulders' width, the subjects were instructed to jump as far as possible, landing with their feet together. f) Waist circumference. As a measure of central body fat, waist circumference was measured in centimetres.

Body composition analyser. Body composition was assessed through bioimpedance and measured using Tanita ${ }^{\circledR}$ Body Composition Monitor model BF-350. This instrument provides body fat and body mass index (BMI) when height is introduced.

T-force System platform. Lower trunk mean propulsive velocity (MVprop) was measured using this force platform (T-Force System, Ergotech, Murcia, Spain) when subjects performed 5 half-squat repetitions using a lightweight wooden barbel with no added weights. The children were given instructions carefully and encouraged verbally to undertake the concentric phase of the athletic movement as quickly as possible. Feedback was provided by an observer, who informed the subject of the velocity reached in each repetition. Six practice sessions were performed before the test.

HR monitor equipped with the corresponding software (Bodyguard, Firstbeat SPORTS software, Jyväskylä, Finland). Excess post-exercise oxygen consumption (EPOC) was estimated after the $20 \mathrm{~m}$ shuttle run test from the variation produced in heart rate (HR). 
All participants were assigned to stage I of Tanner's development stage $\mathrm{e}^{41,42}$

\section{Training interventions}

\section{Intervention group $(I G)$}

Subjects in the IG participated in an interval training program for 12 weeks, which consisted of 2 sessions of 40 minute duration per week. Each session involved 20 minutes of high-intensity intermittent exercises (around 10-20 s) and 20 minutes of sports activities as described in prior studies by Faigenbaum and $\mathrm{Myer}^{33}$, Behringer, Vom Heede, Yue, Mester ${ }^{29}$, Baquet, Van Praagh, Berthoin ${ }^{27}$ and Baquet, Guinhouya, Dupont, Nourry, Berthoin ${ }^{26}$. Following a standard warm-up, sessions commenced with several sets of half-squats followed by sprints and a training circuit consisting of jumps, speed/ agility tasks, carrying weights, pulling exercises, etc. Activities were performed as games or in a competitive manner and participants were constantly encouraged verbally to perform the high-intensity exercises with maximum effort. The details of the HIIT performed in each session are provided in Table 1. Workloads and stimuli in each session were carefully designed for maximum efficiency ${ }^{16}$.

\section{Control group (CG)}

The CG subjects underwent the same 12 week extracurricular training program, but instead of completing 20 minutes of interval exercises they took part in 20 minutes of moderateintensity aerobic exercises and games; this was also followed by 20 minutes of sport.

Table 1. Details of the first 20 minutes of each high-intensity interval training (HIIT) session carrying weights, pulling exercises

\begin{tabular}{|c|c|c|c|}
\hline Session & HIIT PROGRAM & Session & HIIT PROGRAM \\
\hline 1 & Half-squats $3 \times 5$ : (barbel 1 ; IRR $2 \mathrm{~min}$ ) & 7 & Half-squats $3 \times 7$ : (barbel 3; IRR $2 \mathrm{~min}$ ) \\
\hline 2 & Sprint $3 \times 15$ m.: IRR 2.5 min Reaction rate activities & 8 & Sprint $4 \times 20$ m.: IRR 2 min Reaction rate activities \\
\hline 3 & $\begin{array}{l}\text { Circuit with times } \\
\text {-S1: Jump with feet together to stand }(50 \mathrm{~cm} \text { high }) \times 2 \\
\text {-S2: In Zic-zac activities } 4 \text { signal cones velocity } \\
\text {-S3: Long jump with stride } \times 2 \\
\text {-S4: Sprint } 3 \mathrm{~m}\end{array}$ & 9 & $\begin{array}{l}\text { Circuit with times } \\
\text {-S1: Jump with feet together to stand }(50 \mathrm{~cm} \text { high }) \times 3 \\
\text {-S2: In Zic-zac activities } 6 \text { signal cones velocity } \\
\text {-S3: Long jump with stride } \times 3 \\
\text {-S4: Sprint } 4 \mathrm{~m}\end{array}$ \\
\hline 4 & Half-squats $3 \times 6$ : (barbel 2 ; IRR $2 \mathrm{~min}$ ) & 10 & Half-squats $3 \times 9$ : (barbel 3; IRR $2 \mathrm{~min}$ ) \\
\hline 5 & Sprint $3 \times 15$ m.: IRR 2.5 min Reaction rate activities & 11 & Sprint $4 \times 25 \mathrm{~m} .:$ IRR $2 \mathrm{~min}$. \\
\hline 6 & $\begin{array}{l}\text { Circuit with times } \\
\text {-S1: Sprint } 1 \mathrm{~m} \text { combined with pulling exercices } \\
\text {-S2: Jump with feet together } 4 \text { hoops } 30 \mathrm{~cm} \text { distance } \\
\text {-S3: Shot put } 2 \mathrm{~kg} \text { at the greatest horizontal distance } \\
\text {-S4: Sprint } 3 \mathrm{~m}\end{array}$ & 12 & $\begin{array}{l}\text { Reaction rate activities } \\
\text { Circuit with times } \\
\text {-S1: Sprint } 2 \mathrm{~m} \text { combined with pulling exercices } \\
\text {-S2: Jump with feet together } 4 \text { hoops } 50 \mathrm{~cm} \text { distance } \\
\text {-S3: Shot put } 3 \mathrm{~kg} \text { at the greatest horizontal distance } \\
\text {-S4: Sprint } 4 \mathrm{~m}\end{array}$ \\
\hline
\end{tabular}

IRR: inter-repetition rest period; m: metres; barbel 1: cushioned $2 \mathrm{~kg}$ bar; barbel 2: cushioned $2.5 \mathrm{~kg}$ bar; barbel 3: cushioned $3 \mathrm{~kg}$ bar.; S: Station; All sessions include a formal initial meeting, which included familiarization with the exercises provided in the session.

\section{Statistical Analysis}

Data are provided as means and their corresponding standard deviations $(M \pm S D)$. The homogeneity of the two study groups in terms of the anthropometric and healthrelated fitness variables recorded at baseline was confirmed by one-way ANOVA. Intervention effects were assessed through ANOVA of pre/post intervention data by examining PA intervention and measurement time point as the independent variables along with their interactions. Significant interactions were subjected to Bonferroni correction. All statistical tests were performed using the software package SPSS version 20.0 for Windows (Chicago, IL, USA). Significance was set at $\mathrm{p}<0.05$.

\section{Results}

The means and standard deviations of the health-related fitness and anthropometric variables recorded before and after the intervention are provided in Tables 2 and 3. The effects of each intervention on the health-related fitness variables are illustrated in Figures 1 and 2, and Tables 4 and 5.

The HIIT intervention led to improved motor capacity (speed/agility), Vpeak, $\mathrm{VO}_{2 \mathrm{~m}}$ ax and EPOC, along with improved musculoskeletal capacity of the lower trunk (MVprop and standing long jump). As may be observed in Tables 2 and 3 , differences in means following the intervention were higher in the GI than in the CG. Both PA programs had no effect on anthropometric or hand strength measurements. 
Table 2. Health-related fitness variables $(\mathrm{M} \pm \mathrm{SD})$ recorded before and after a 12 week extracurricular, moderate-intensity training (MIT) or highintensity interval training (HIIT) program.

\begin{tabular}{ccccc} 
& & CG & Total & CG \\
& Before & $9.4 \pm 0.55$ & $9.5 \pm 0.45$ & $9.4 \pm 0.43$ \\
Vpeak $(\mathrm{Km} / \mathrm{h})$ & After & $10.6 \pm 1.11$ & $10.1 \pm 0.56$ & $10.3 \pm 0.94$ \\
& Before & $46.4 \pm 2.51$ & $47.0 \pm 2.50$ & $46.8 \pm 2.50$ \\
VO2 max (indirect) $(\mathrm{ml} / \mathrm{kg} / \mathrm{min})$ & After & $51.5 \pm 4.91$ & $49.6 \pm 3.59$ & $50.4 \pm 4.26$ \\
& Before & $23.7 \pm 12.83$ & $23.2 \pm 14.82$ & $23.4 \pm 13.97$ \\
EPOC $(\mathrm{ml} / \mathrm{kg})$ & After & $37.2 \pm 27.41$ & $25.8 \pm 23.84$ & $30.3 \pm 25.80$ \\
& Before & $15.84 \pm 1.29$ & $15.45 \pm 1.72$ & $15.61 \pm 1.60$ \\
Speed/agility $(\mathrm{s})$ & After & $14.79 \pm 1.43$ & $15.56 \pm 1.65$ & $15.24 \pm 1.60$ \\
Standing long jump $(\mathrm{cm})$ & Before & $139.7 \pm 16.53$ & $138.7 \pm 14.85$ & $139.10 \pm 15.46$ \\
MVprop $(\mathrm{m} / \mathrm{s})$ & After & $149.3 \pm 20.34$ & $139.3 \pm 21.87$ & $143.31 \pm 21.73$ \\
& Before & $1.18 \pm 0.19$ & $1.11 \pm 0.24$ & $1.14 \pm 0.22$ \\
Dynamometry left hand $(\mathrm{kg})$ & After & $1.21 \pm 0.23$ & $13.7 \pm 3.23$ & $1.08 \pm 0.28$ \\
& Before & $12.8 \pm 2.20$ & $13.7 \pm 4.38$ & $13.3 \pm 2.89$ \\
Dynamometry right hand $(\mathrm{kg})$ & After & $13.5 \pm 3.38$ & $14.7 \pm 3.41$ & $13.6 \pm 3.99$ \\
& Before & $14.0 \pm 2.71$ & $14.4 \pm 4.52$ & $14.4 \pm 3.15$ \\
\hline
\end{tabular}

Vpeak: peak velocity; $\mathrm{VO}_{2 \mathrm{~m}}$ ax: maximum oxygen consumption; EPOC: excess post-exercise peak oxygen consumption; MVprop: mean propulsive velocity

Table 3. Anthropometric variables $(\mathrm{M} \pm \mathrm{SD})$ recorded before and after a 12-week, extracurricular, moderate-intensity training (MIT) or highintensity interval training (HIIT) program.

\begin{tabular}{ccccc}
\hline & & IG & CG & Total \\
\hline \multirow{2}{*}{ Body mass index $\left(\mathrm{kg} / \mathrm{m}^{2}\right)$} & Before & $17.8 \pm 3.4$ & $18.1 \pm 3.7$ & $18.0 \pm 3.6$ \\
& After & $18.8 \pm 3.6$ & $18.8 \pm 3.6$ & $18.8 \pm 3.6$ \\
Body fat $(\%)$ & Before & $18.7 \pm 7.9$ & $19.8 \pm 8.9$ & $19.3 \pm 8.5$ \\
\multirow{2}{*}{ Waist circumference $(\mathrm{cm})$} & After & $22.5 \pm 8$ & $22.5 \pm 9.1$ & $22.5 \pm 8.6$ \\
& Before & $61.2 \pm 8.7$ & $62.9 \pm 7.9$ & $62.2 \pm 8.2$ \\
& After & $62.9 \pm 8.5$ & $62.4 \pm 6.7$ & $62.6 \pm 7.5$ \\
\hline
\end{tabular}

No significant differences were detected when Vpeak values between the two interventions were compared $\left(\mathrm{F}_{1,79}=1.927\right.$; $\left.\eta^{2}=0.024 ; 1-\beta=0.279 ; p=0.169\right)$ though differences were observed between pre - and post-intervention values $\left(\mathrm{F}_{1,79}=155.88 ; \eta^{2}=0.664\right.$; $1-\beta=1.000 ; p=0.001$ ) and for the interaction between time point and intervention $\left(\mathrm{F}_{1,79}=12.306 ; \eta^{2}=0.135 ; 1-\beta=0.934 ; p=0.001\right)$. When Vpeak values between the $C G$ and IG were compared, no significant differences were recorded before the intervention $(p=0.627)$, but differences did emerge after the intervention $(p=0.002)$. In addition, both groups showed significant effects of the intervention when pre-and post-intervention data were compared ( $\mathrm{IG} p=0.001 ; \mathrm{CG} p=0.001$ ).
$\mathrm{VO}_{2 \mathrm{~m}}$ ax values differed significantly, both according to the measurement time point $\left(\mathrm{F}_{1,79}=129.697\right.$; $\left.\eta^{2}=0.621 ; 1-\beta=0.9999 ; p=0.001\right)$ and its interaction with the intervention $\left(\mathrm{F}_{1,79}=15.370 ; \eta^{2}=0.163 ; 1-\beta=0.972 ; p=0.001\right)$. No differences in $\mathrm{VO}_{2}$ were recorded according to the type of intervention $\left(\mathrm{F}_{1,79}=0.757 ; \eta^{2}=0.009 ; 1-\beta=0.138\right.$; $p=0.387)$. Paired comparisons revealed an effect of the time point (pre - vs post-intervention) in both groups (IG $p=0.001$; $\mathrm{CG} p=0.001$ ) along with differences between groups in post-intervention $\mathrm{VO}_{2 \mathrm{~m}}$ ax values $(p=0.044)$, but not preintervention values $(p=0.207)$.
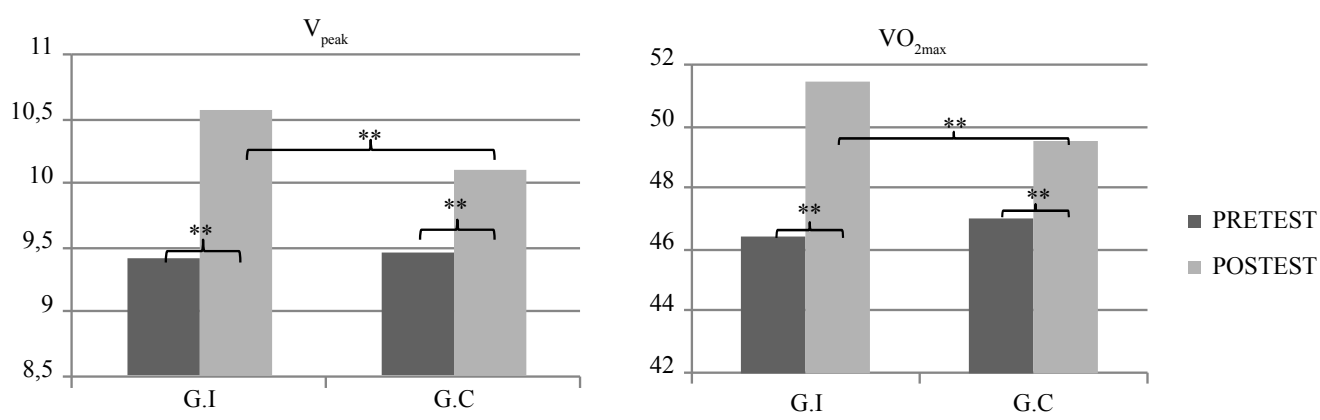

Figure 1. Vpeak and $\mathrm{VO}_{2 \mathrm{~m}}$ ax values recorded in the $20 \mathrm{~m}$ shuttle sprint test before and after the control and high-intensity interval training programs $(* * \mathrm{p}<.01 ; * \mathrm{p}<.05)$. 
EPOC values varied according to the measurement time point and the interaction time point $\mathrm{x}$ intervention. No effects were observed of the intervention type (see Table 4). Preintervention EPOC values failed to vary between the groups
( $p=0.560)$, but post-intervention values varied $(p=0.050)$. No differences in pre - and post-intervention EPOC values were recorded in the $\mathrm{CG}(p=0.534)$, but differences were detected in the IG $(p=0.001)$.

Table 4. Statistics obtained for excess post-exercise oxygen consumption

\begin{tabular}{ccccccccc}
\hline & $\mathbf{F}_{\mathbf{1 , 7 9}}$ & $\boldsymbol{\eta}^{2}$ & $\mathbf{1 - \beta}$ & $\mathbf{p}$ & & \multicolumn{3}{c}{ Pairwise comparisons } \\
EPOC & & & & & & CG/IG & CG \\
Before/After & 16.254 & 0.171 & 0.978 & $0.001^{* *}$ & Before & 0.560 & IG \\
PA intervention & 1.323 & 0.016 & 0.206 & 0.254 & After & $0.050^{*}$ & 0.534 \\
Interaction & 10.534 & 0.118 & 0.894 & 0.002 & Before/After & & $0.001^{* *}$ \\
\hline
\end{tabular}

$(* * \mathrm{p}<.01 ; * \mathrm{p}<.05)$

Similarly, when we compared the results of the $4 \times 10$ $\mathrm{m}$ speed/agility test, significant effects were observed of the measurement time point $\left(\mathrm{F}_{1,85}=11.398 ; \eta^{2}=0.018 ; 1-\beta\right.$ $=0.916 ; p=0.001)$ and of the interaction time point $\mathrm{x}$ intervention $\left(\mathrm{F}_{1,85}=17.483 ; \eta^{2}=0.171 ; 1-\beta=0.985 ; p=0.001\right)$. No effects of the intervention were noted $\left(\mathrm{F}_{1,85}=0.291\right.$; $\left.\eta^{2}=0,003 ; 1-\beta=0.083 ; p=0.591\right)$. In the Bonferroni test comparisons, speed/agility showed no inter-group differences before the intervention $(p=0.219)$, but did differ after the intervention $(p=0.027)$. Differences between the two time points were not observed in the $\mathrm{CG}(p=0.533)$, yet were detected in the IG $(p=0.001)$.
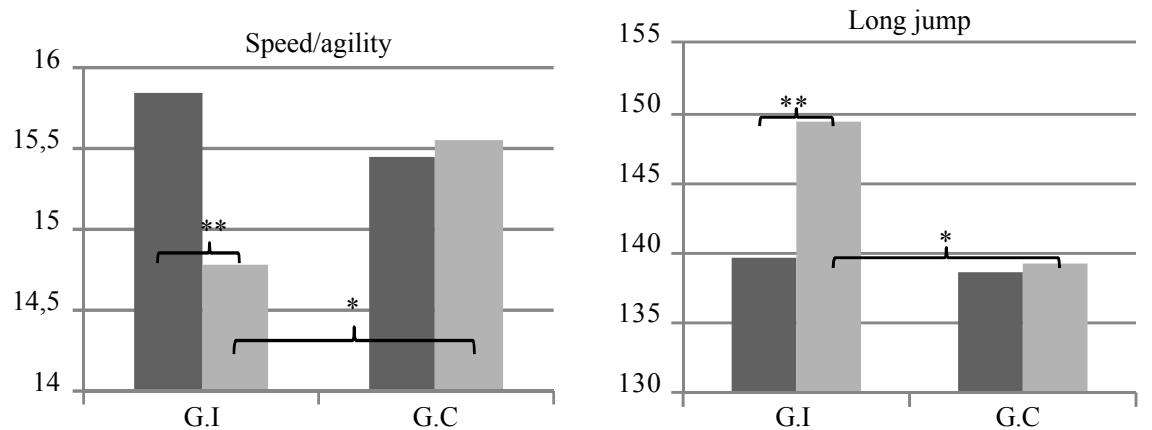

PRETEST

POSTEST

Figure 2. Speed/agility and standing long jump values recorded in the Alpha fitness test battery before and after the control and high-intensity interval training programs $(* * \mathrm{p}<.01 ; * \mathrm{p}<.05)$

Standing long jump results differed significantly according to both the measurement time point $\left(\mathrm{F}_{1,90}=8.019\right.$; $\left.\eta^{2}=0.082 ; 1-\beta=0.800 ; p=0.006\right)$ and the interaction time point $\mathrm{x}$ intervention $\left(\mathrm{F}_{1,90}=6.095 ; \eta^{2}=0.063 ; 1-\beta=0.685\right.$; $p=0.015)$. No effects of the intervention were detected $\left(\mathrm{F}_{1,90}\right.$ $\left.=2.237 ; \eta^{2}=0.024 ; 1-\beta=0.316 ; p=0.138\right)$. Bonferroni test comparisons revealed no differences between the CG and IG in pre-intervention long jump results $(p=0.768)$, yet differences in post-intervention results were observed $(p=0.036)$. No differences in before/after long jump distances were detected in the CG $(p=0.772)$, but these emerged in the IG $(p=0.001)$ (see Figure 2). MVprop varied according to the intervention and the interaction time point $\mathrm{x}$ intervention. After the intervention, this variable decreased in the CG to provide before/ after differences ( $p=0.001)$ whereas MVprop showed a slight increase in the IG (see Tables 2 and 5).

Table 5. Statistics obtained for lower trunk musculoskeletal capacity

\begin{tabular}{|c|c|c|c|c|c|c|c|c|}
\hline & $F_{1,81}$ & $\eta^{2}$ & $1-\beta$ & $\mathbf{P}$ & & Pairwise & parisons & \\
\hline MVprop & & & & & & $\mathrm{CG} / \mathrm{IG}$ & $\mathrm{CG}$ & IG \\
\hline Before/After & 3.763 & 0.044 & 0.483 & 0.056 & Before & 0.227 & & \\
\hline PA intervention & 8.658 & 0.097 & 0.828 & $0.004 * *$ & After & $0.001 * *$ & & \\
\hline Interaction & 8.390 & 0.094 & 0.816 & $0.005 * *$ & Before/ after & & $0.001 * *$ & 0.531 \\
\hline
\end{tabular}

$* * \mathrm{p}<.01 ; * \mathrm{p}<.05$

No significant effects were produced on the dynamometer results of the measurement time point (left hand $\mathrm{F}_{1,90}=0.927$, $\eta^{2}=0.010 ; 1-\beta=0.159, p=0.338$; right hand $\mathrm{F}_{1,89}=0.012, \eta^{2}=0.0001$, $1-\beta=0.051, p=0.912$ ), intervention (left hand $F_{1,90}=0.728$, $\eta^{2}=0.008 ; 1-\beta=0.135, p=0.396$; right hand $\mathrm{F}_{1,89}=0.257, \eta^{2}=0.003$, $1-\beta=0.079, p=0.613$ ) or interaction time point $\mathrm{x}$ intervention (left hand $\mathrm{F}_{1,90}=0.953, \eta^{2}=0.010,1-\beta=0.162, p=0.332$; right hand $\left(\mathrm{F}_{1,89}=0.486, \eta^{2}=0.005,1-\beta=0.106, p=0.488\right)$. 
The anthropometric variables examined increased both in the IG and CG (see Table 3). Significant differences in BMI values were observed for the different measurement time points $\left(F_{1,83}=22.550 ; \eta^{2}=0.214 ; 1-\beta=0.997 ; p=0.001\right)$, yet no changes were observed according to intervention type $\left(\mathrm{F}_{1,83}=0.021\right.$; $\left.\eta^{2}=0.0001 ; 1-\beta=0.052 ; p=0.885\right)$ or the interaction between time point and intervention $\left(\mathrm{F}_{1,83}=0.101 ; \eta^{2}=0.001 ; 1-\beta=0.061\right.$; $p=0.752)$. The percentage of body fat varied similarly according to the time point $\left(\mathrm{F}_{1,83}=55.488 ; \eta^{2}=0.401 ; 1-\beta=0.9999\right.$; $p=0.001)$, but not according to the intervention $\left(\mathrm{F}_{1,83}=0.002\right.$; $\left.\eta^{2}=0.0001 ; 1-\beta=0.050 ; p=0.965\right)$ or the interaction time point $\mathrm{x}$ intervention $\left(\mathrm{F}_{1,83}=0.060 ; \eta^{2}=0.001 ; 1-\beta=0.057\right.$; $p=0.807)$. Waist circumference failed to vary significantly according to the time point $\left(\mathrm{F}_{1,83}=3.720 ; \eta^{2}=0.043 ; 1-\beta=0.479\right.$; $p=0.057)$, intervention $\left(\mathrm{F}_{1,83}=0.001 ; \eta^{2}=0.0001 ; 1-\beta=0.050\right.$; $p=0.970)$, or interaction time point $\mathrm{x}$ interaction $\left(\mathrm{F}_{1,83}=2.447\right.$; $\left.\eta^{2}=0.029 ; 1-\beta=0.340 ; p=0.122\right)$.

\section{Discussion}

The main findings of this study were that a 12 week extracurricular strength training program consisting of controlled workloads adapted for children was more able to improve several health-related fitness variables than the effects of a more conventional lower intensity PA program. The high-intensity interval activities undertaken in the training intervention led to significant improvements in Vpeak, $\mathrm{VO}_{2 \mathrm{~m}}$ ax, EPOC and lower trunk MVprop as well as in the performance of speed/agility tests and long jump.

All the variables recorded after a $20 \mathrm{~m}$ shuttle run test was significantly improved in the intervention group. The effects produced on both Vpeak and $\mathrm{VO}_{2 \mathrm{~m}}$ ax resemble those described in a large number of studies $22,26,43,44$. Despite improvements in postintervention $\mathrm{VO}_{2 \mathrm{~m}}$ ax values recorded in both our intervention and control groups, the greatest effects were produced in the IG to the extent that significant post-intervention differences were observed with respect to the CG despite even lower pre-intervention values (see Figure 1). These findings are consistent with the conclusions arrived at by Baquet, Van Praagh, Berthoin ${ }^{27}$, who reported that the $\mathrm{VO}_{2 \mathrm{~m}}$ ax improvement produced in response to the aerobic PA generally undertaken by children in this age group is reduced in comparison to the effects of high-intensity short-duration activities on the cardiovascular health of children. In effect, intermittent exercises performed at maximum intensity may be observed in a child's spontaneous activity ${ }^{45}$. In a study by Bailey, Olson, Pepper, Porszasz, Barstow, Cooper ${ }^{46}$, it was found that the mean duration of the physical activities of children between the ages of 6 and 10 years was no more than 3 seconds (under 15 seconds in $95 \%$ of cases) and that intensities were high. Many authors have attributed the lower anaerobic performance of children to a non fully-developed glucose metabolism pathway ${ }^{47,48}$, thus, contraindicating high-intensity PA. However, the results of several studies seem to challenge this idea ${ }^{49-51}$. Accordingly, Van Praagh and Doré ${ }^{1}$ argued that lower blood and muscle lactate concentrations in children may be explained by the lower muscle mass involved in physical exercise. According to Ratel et al. ${ }^{45}$, there is no sound physiological evidence to indicate that high-intensity exercise could be harmful for children and these authors endorsed this type of program based on their observation of appreciable effects on both the aerobic and anaerobic capacity of prepubertal children. These findings are in line with the present results. The Vpeak and $\mathrm{VO}_{2 \mathrm{~m}}$ ax improvements observed are related to the EPOC values attained by our subjects. During the stage of recovery following exercise, calorie intake increases and this increase is maintained until all metabolic processes return to their baseline state. In our study, EPOC were recorded during the rapid stage of oxygen consumption within the initial hour of recovery ${ }^{52,53}$. The highest post-intervention EPOC levels recorded in the IG may be related to a greater metabolic disruption ${ }^{54}$ as a consequence of the increased oxygen consumption or $\mathrm{VO}_{2 \mathrm{~m}}$ ax, during the $20 \mathrm{~m}$ sprint. Descriptive studies in adults such as those of Bahr, Grønnerød, Sejersted ${ }^{55}$ and Laforgia, Withers, Shipp, Gore ${ }^{56}$ have shown that the intensity at which an exercise is executed ( $3 \times 2$ min on a cycle ergometer at $108 \% \mathrm{VO}_{2 \mathrm{~m}}$ ax; $20 \times 1$ minute sprints at $105 \% \mathrm{VO}_{2 \mathrm{~m}}$ ax, respectively) will affect excess postexercise oxygen consumption significantly. In a review of the effects of the exercise intensity, duration and modality on excess post-exercise oxygen consumption, Borsheim and Bahr ${ }^{52}$ reported that high-intensity activities significantly increase EPOC values, thus, supporting the results of our intervention. Despite the frequent use of this variable in adults, as far as we know no such data are available for children precluding any comparisons.

Besides the beneficial cardiovascular effects observed, our HIIT program also led to better agility/velocity levels (see Figure 2). Other authors have also described a link between cardiovascular status and other fitness-related factors including agility/velocity ${ }^{26,57-59}$. In contrast, Ardoy et al. ${ }^{60}$ observed no such improvement in pairwise comparisons in two experimental groups despite high-intensity exercise in one of the groups reflected by a high mean heart rate.

Among the factors related to muscular-skeletal capacity, we detected significant improvements in the explosive force generated in the legs, both in the standing long jump test and in the variable MVprop. Thus, following the intervention, subjects in the IG covered a significantly longer distance in the long jump compared to those in the CG (see Figure 2). These data are consistent with those reported by Baquet, Guinhouya, Dupont, Nourry, Berthoin ${ }^{26}$, Secchi, García, España-Romero, Castro-Piñero ${ }^{59}$ and Cuenca-García et al. ${ }^{37}$, which the beneficial effects of a HIIT program on lower trunk strength. The mean propulsive velocity, MVprop, was unaffected by the intervention, most likely because of the instability experienced doing squat exercises at this age.

Our study has several limitations. For the post-intervention tests, our CG subjects had less practice at the half-squats than their peers in the IG. In addition, the HIIT intervention should have included exercises designed to improve upper limb strength. Finally, owing to the time available for the PA sessions, HR data could not be obtained during the strength training exercises such that the work intensity during the proposed strength training program could not be determined accurately. 
In conclusion, the findings of our study indicate that short-duration high-intensity neuromuscular exercises are an effective option to improve the health-related physical fitness of school children. To date, this kind of program has only been implemented in sports' clubs and teams in which population bias exists due to the level of motor competence. Hence, this type of training program in an education setting, whether curricular or extracurricular, would be a powerful tool to improve the physical fitness of children, regardless of their unwillingness to participate in sport. More work in the field is needed with special emphasis on aspects such as motivation levels during longer-duration programs and levels of adherence to such programs.

\section{References}

1. Janssen I. Physical activity guidelines for children and youth. APNM. 2007; 32: 109-121.

2. Ortega F, Ruiz J, Castillo M, Moreno L, Gonzalez-Gross M, Wärnberg J. et al. Bajo nivel de forma física en los adolescentes españoles. Importancia para la salud cardiovascular futura (Estudio AVENA). Rev Esp Cardiol. 2005; 58(8): 898-909.

3. Reverter J, Plaza D, Jové C, Hernández V. Actividad físico-deportiva extraescolar en alumnos de primaria: el caso de Torrevieja (Alicante). Retos. 2014; 25: 48-52.

4. Troiano RP, Berrigan D, Dodd KW, Masse LC, Tilert T, McDowell M. Physical activity in the United States measured by accelerometer. Med Sci Sports Exerc. 2008; 40(1): 181-188.

5. Escalante Y, Saavedra J, García-Hermoso A, Domínguez A. Improvement of the lipid profile with exercise in obese children: A systematic review. PrevMed. 2012; 54: 293-301.

6. García-Cantó E, Pérez JJ. Programa para la promoción de actividad física saludable en escolares murcianos. Retos. 2014; 25: 131-135

7. González J, Portolés A. Actividad física extraescolar: relaciones con la motivación educativa, rendimiento académico y conductas asociadas a la salud. RIPED. 2014; 1 (9): 51-65.

8. Annesi J, Faigenbaum A, Westcott W, Smith A, Unruh J, Hamilton F. Effects of the Youth Fit For Life protocol on physiological, mood, self-appraisal, and voluntary physical activity changes in African American preadolescents: Contrasting after-school care and physical education formats. Int J Clin Hlth Psyc. 2007; 3: 641-659.

9. Cordova A, Villa G, Sureda A, Rodriguez-Marroyo JA, SanchezCollado P. Actividad física y factores de riesgo cardiovascular de niños españoles de 11-13 años. Rev Esp Cardiol. 2012; 65 (7): 620-626.

10. Hasselstrøm H, Karlsson M, Hansen S, Grønfeldt V, Froberg K, Andersen L. A 3-Year Physical Activity Intervention Program Increases the Gain in Bone Mineral and Bone Width in Prepubertal Girls but not Boys: The Prospective Copenhagen School Child Interventions Study (CoSCIS). Calc Tiss Res. 2008; 83: 243-250.

11. Hogg J, Diaz A, Cid M, Mueller C, Grace E, Cheruvu S. et al. An after-school dance and lifestyle education program reduces risk factors for heart disease and diabetes in elementary school children. J Pediatr Endocr Met. 2012; 25(5-6): 509-516.

12. Resaland GK, Anderssen LB, Mamen A, Anderssen SA. Effects of a 2-year school-based daily physical activity intervention on cardiorespiratory fitness. The Sogndal school-intervention study. Scand J Med Sci Spor. 2011; 21: 302-309.

13. Colín-Ramírez E, Castillo-Martínez L, Orea-Tejeda A, VergaraCastañeda A, Keirns-Davis C, Villa-Romero A. Outcomes of a school-based intervention (RESCATE) to improve physical activity patterns in Mexican children aged 8-10 years. Health Educ Res. 2010; 25 (6): 1042-1049.

14. Wright K, Giger JN, Norris K, Suro Z. Impact of a nurse-directed, coordinated school health program to enhance physical activity behaviours and reduce body mass index among minority children: A parallel-group, randomized control trial. Int J Nurs Stud. 2012; 50 (6): 727-737

15. Leek D, Carlson J, Cain K, Henrichon S, Rosenberg D, Patrick K. et al. Physical Activity During Youth Sports Practices. Arch Pediatr Adolesc Med. 2010; 4 (165): 294-299.

16. Myer GD, Faigenbaum AD. Exercise is sports medicine in youth: Integrative neuromuscular training to optimize motor development and reduce risk of sports related injury. Kronos. 2010; 10 (1): 39-48.

17. Ben Ounis O, Elloumi M, Zouhal H, Makni E, Denguezli M, Amri M, Lac G, Tabka Z. Effect of individualized exercise training combined with diet restriction on inflammatory and igf-1/igfbp-3 in obese children. Ann Nutr Metab. 2010; 56: 260-266.

18. Kriemler S, Zahner L, Schindler C, Meyer U, Hartmann T, Hebestreit H, Brunner-La Rocca H, Van Mechelen W, Puder J. Effect of school based physical activity programme (KISS) on fitness and adiposity in primary schoolchildren: cluster randomised controlled trial. BMJ. 2010; 340: 1-8.

19. Sandercock G, Cohen D, Griffin M. Evaluation of a multicomponent intervention to improve weight status and fitness in children: Upstarts. Pediatr Int. 2012; 6 (54): 911-917.

20. Sigmund E, El Ansari W, Sigmundová D. Does school-based physical activity decrease overweight and obesity in children aged $6 ; 9$ years? A two-year non-randomized longitudinal intervention study in the Czech Republic. BMC Public Health. 2012; 1 (12): 570-583.

21. Faigenbaum A, Westcott W, LaRosa R, Long C. The Effects of Different Resistance Training Protocols on Muscular Strength and endurance development in children. Pediatrics. 2005; 1 (104): 1-7.

22. Gamelin FX, Baquet G, Berthoin S, Thevenet D, Nourry C, Nottin $\mathrm{S}$, Bosquet L. Effect of high intensity intermittent training on heart rate variability in prepubescent children. Eur J Appl Physiol. 2009; 105: 731-738.

23. Nourry C, Deruelle F, Guinhouya C, Baquet G, Fabre C, Bart F, Berthoin S, Mucci P. High-intensity intermittent running training improves pulmonary function and alters exercise breathing pattern in children. Eur J Appl Physiol. 2005; 94(4): 415-23.

24. Rosenkranz R, Welk G, Dzewaltowski D. Environmental correlates of objectively measured physical activity and sedentary behaviour in after-school recreation sessions. JPAH. 2011; 8: 214-221.

25. Yu C, Sung YT, So R, Lui KC, Lau W, Lam P, Lau E. Effects of Strength Training on Body Composition and Bone Mineral Content in Children Who Are Obese. J Strength Cond Res. 2005; 19(3): 667-672

26. Baquet G, Guinhouya C, Dupont G, Nourry C, Berthoin S. Effects of a short-term interval training program on physical fitness in prepubertal children. J Strength Cond Res. 2004; 18(4): 708-713 
27. Baquet G, Van Praagh E, Berthoin S. Endurance Training and Aerobic Fitness in Young People. Sports Med. 2003; 33(15): 1127-1143.

28. Naclerio F, Faigenbaum A. Integrative neuromuscular training for youth. Kronos. 2011; 10 (1): 49-56.

29. Behringer M, Vom Heede A, Yue Z, Mester J. Effects of resistence training in children an adolescents: a metaanálisis. Pediatrics. 2010; 126 (5): 199-210.

30. Faigenbaum A, Myer GD. Resistence training among young athletes: safety, efficacy an injury prevention effects. Br J Sports Med. 2009; 44: 56-63

31. Slining M, Adair LS, Goldman BD, Borja JB, Bentley M. Infant overweight is associated with delayed motor development. J Pediatric. 2010; 157: 20-25.

32. Mickle KJ, Munro BJ, Steele JR. Gender and age affect balance performance in primary school-aged children. J Sci Med Sport. 2011; 14: 243-248.

33. Faigenbaum A, Myer GD. Resistance training and paediatric health. Kronos. 2011; 10 (1): 31-38.

34. Donnelly J, Jacobsen D, Whatley J, Hill J, Swift L, Cherrington A, Polk B, Tran Z, Reed G. Nutrition and physical activity program to attenuate obesity and promote physical and metabolic fitness in elementary school children. Obes Res. 2012; 3 (4): 229-243.

35. Gortmaker S, Lee R, Mozaffarian R, Sobol A, Nelson T, Roth B, Wiecha J. Effect of an After-School Intervention on Increases in Children's Physical Activity. Med Sci Sport Exer. 2012; 44(3): 450-457.

36. McMinn D, Rowe DA, Murtagh S, Nelson NM. The effect of a school-based active commuting intervention on children's commuting physical activity and daily physical activity. Prev Med. 2012; 15 (54): 316-318.

37. Cuenca-García M, Jiménez-Pavón D, España-Romero V, Artero E, Castro-Peñero JC, Ortega F, Ruiz JR, Castillo M. Condición física relacionada con la salud y hábitos de alimentación en niños y adolescentes: propuesta de addendum al informe de salud escolar. Rev Invest Ed. 2011; 9 (2): 35-50.

38. Serra-Paya N, Ensenyat A, Real J, Castro-Viñuales I, Zapata A, Galindo G, Solé-Mir E, Bosch-Muñoz J, Mur JM, Teixido C. Evaluation of a family intervention programme for the treatment of overweight and obese children (Nereu Programme): a randomized clinical trial study protocol. BMC Public Health. 2013; 13: 1-14.

39. Torrijos-niño C, Martínez-Vizcaino V, Pardo-Guijarro MJ, García-Prieto JC, Arias-Palencia NM, Sánchez-López M. Physical Fitness, Obesity, and Academic Achievement in Schoolchildren. J Pediatr. 2014; 1 (165): 104-109.

40. Leger LA, Mercier D, Gadoury C, Lambert J. The multistage 20 metres shuttle run test for aerobic fitness. J Sport Sci. 1988; 6: 93-101.

41. Muñoz MT, Pozo J. Pubertad normal y sus variantes. Pediatr Integral. 2011; 15 (6): 507-518.

42. Tanner JM. The measurement of maturity. Trans Eur Orthod Soc. 1975 ; 45-60.

43. Baquet G, Berthoin S, Dupont G, Blondel N, Fabre C, Van Praagh E. Effects of high intensity intermittent training on peak VO (2) in prepubertal children. Int J Sports Med. 2012; 23(6): 439-44
44. Berthoin S, Baquet G, Dupont G, Van Praagh E. Critical velocity during continuous and intermittent exercises in children. Eur J Appl Physiol. 2006; 98: 132-138.

45. Ratel S, Lazaar N, Dore E, Baquet G, Williams C, Berthoin S. et al. High-intensity intermittent activities at school: controversies and facts. J Sport Med Phys Fit. 2004; 44: 272-280.

46. Bailey R, Olson J, Pepper S, Porszasz J, Barstow T, Cooper D. The level and tempo of children's physical activities: an observational study. Med Sci Sport Exer. 1995; 7 (27):1033-1041.

47. Falgairette G, Bedu M, Fellman N, Van Praagh E, Coudert J. Bioenergetic profile in 144 boys aged from 6 to 15 years with special reference to sexual maturation. Eur J Appl Physiol. 1991; 62: 151-156.

48. Van Praag E, Doré E. Short-term muscle power during growth and maturation. Sports Med. 2002; 32: 701-708.

49. Armstrong N, Welsman JR, Kirby BJ. Performance on the Wingate anaerobic test and maturation. Pediatr Exerc Sci. 1997; 9: 253-261.

50. Petersen SR, Gaul CA, Stanton MM., Hanstock CC. Skeletal muscle metabolism during short-term, high-intensity exercise in prepuberal and pubertal girls. J Appl Physiol. 1999; 21 (87): 51-56.

51. Van Praagh E, Bedu M, Falgairette G, Fellmann N, Coudert J. Oxygen uptake during a 30 -s supramaximal exercise in 7 to 15-year-old boys. In: R Frenkl, 1 editor. Children and exercise XV. Budapest: Natl Inst for health promotion. 1991; 281-287.

52. Børsheim E, Bahr R. Effect of Exercise Intensity, Duration and Mode on Post-Exercise Oxygen Consumption. Sports. 2003; 14 (33): 1037-1060.

53. Lamont LS, Romito R, Rossi K. Fat-free mass and gender influences the rapid-phase excess postexercise oxygen consumption. Appl Physiol Nutr Me. 2010; 35 (1): 23-26.

54. Earnest CP, Scott CB. Resistance Exercise Energy Expenditure is Greater with Fatigue as Compared to Non-Fatigue. JEPonline. 2011; 14 (1): 1-10.

55. Bahr R, Grønnerød O, Sejersted OM. Effect of supramaximal exercise on excess postexercise O2 consumption. Med Sci Sport Exercise. 1992; 1 (24): 66-71.

56. Laforgia J, Withers T, Shipp J, Gore J. Comparison of energy expenditure elevations after submaximal and supramaximal running. J. Appl. Physiol. 1997; 2 (82): 661-666.

57. Ara I, Rodriguez V, Perez-Gomez J, Jimenez-Ramirez J, SerranoSanchez JA, Dorado C, Calbet J. Influence of extracurricular sport activities on body composition and physical fitness in boys: a 3-year longitudinal study. Int J Obesity. 2006; 30: 1062-1071.

58. Ortega F, Ruiz JR, Castillo MJ, Moreno LA, González-Gross M, Wärnberg J, Gutiérrez À. Bajo nivel de forma física en los adolescentes españoles.Importancia para la salud cardiovascular futura (Estudio AVENA). Rev Esp Cardiol. 2005; 58(8): 898-909.

59. Secchi JD, García C, España-Romero V, Castro-Piñero J. Condición física y riesgo cardiovascular futuro en niños y adolescentes argentinos: una introducción de la batería ALPHA. Arch Argent Pediatr. 2014; 112 (2): 132-140

60. Ardoy D, Fernández-Rodríguez JM, Ruiz JR, Chillón P, EspañaRomero V, Castillo M, Ortega F. Mejora de la condición física en adolescentes a través de un programa de intervención educativa: Estudio EDUFIT. Rev Esp Cardiol. 2011; 64 (6): 484-491. 


\section{Corresponding author}

Sergio Reloba Martínez

Doctor en Educación física Departamento Educación Física y deportiva, Facultad de Ciencias de la Actividad física y la Salud. Universidad de Granada (España).

Email: Reloba.s@gmail.com

Manuscript received on October 12, 2014

Manuscript accepted on June 20, 2016

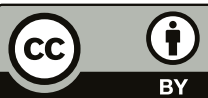

Motriz. The Journal of Physical Education. UNESP. Rio Claro, SP, Brazil - eISSN: 1980-6574 - under a license Creative Commons - Version 3.0 